\title{
Locoregional Therapies of Cholangiocarcinoma
}

\author{
Christof M. Sommer ${ }^{\mathrm{a}, \mathrm{b}}$ Hans-Ulrich Kauczor ${ }^{\mathrm{a}}$ Philippe L. Pereira ${ }^{\mathrm{c}}$ \\ a Clinic for Diagnostic and Interventional Radiology, University Hospital Heidelberg, Heidelberg, Germany; \\ ${ }^{b}$ Clinic for Diagnostic and Interventional Radiology, Klinikum Stuttgart, Stuttgart, Germany; \\ ${ }^{c}$ Clinic for Radiology, Minimally Invasive Therapies and Nuclear Medicine, SLK Kliniken Heilbronn GmbH, Heilbronn, Germany
}

\section{Keywords}

Cholangiocarcinoma - Radiofrequency ablation, RFA .

Microwave ablation, MWA . Hepatic artery infusion, HAI .

Transarterial chemoembolization, TACE .

Transarterial radioembolization, TARE

\section{Summary}

Background: Cholangiocarcinoma (CC) is the second most primary liver malignancy with increasing incidence in Western countries. Currently, surgical RO resection is regarded as the only potentially curative treatment. The results of systemic chemotherapy and best supportive care (BSC) in patients with metastatic disease are often disappointing in regard to toxicity, oncologic efficacy, and overall survival. In current practice, the use of different locoregional therapies is increasingly more accepted. Methods: A review of the literature on locoregional therapies for intrahepatic cholangiocarcinoma (ICC) was undertaken. Results: There are no prospective randomized controlled trials. For localized ICC, either primary or recurrent, radiofrequency ablation (RFA) is by far the most commonly used thermal ablation modality. Thereby, a systematic review and meta-analysis reports major complication in $3.8 \%$ as well as $1-, 3-$, and 5 -year overall survival rates of 82,47 , and $24 \%$, respectively. In selected patients (e.g. with a tumor diameter of $\leq 3 \mathrm{~cm}$ ), oncologic efficacy and survival after RFA are comparable with surgical resection. For diffuse ICC, different transarterial therapies, either chemotherapy-based (hepatic artery infusion (HAI), transarterial chemoembolization (TACE)) or radiotherapy-based (transarterial radioembolization (TARE)), show extremely promising results. With regard to controlled trials (transarterial therapy versus systemic chemotherapy, BSC or no treatment), tumor control is virtually always better for transarterial therapies and very often accompanied by a dramatic survival benefit and improvement of quality of life. Of note, the latter is the case not only for patients without extrahepatic metastatic disease but also for those with liver-dominant extrahepatic metastatic disease. There are other locoregional therapies such as microwave ablation, irreversible electroporation, and chemosaturation; however, the current data support their use only in controlled trials or as last-line therapy. Conclusion: Dedicated locoregional therapies are commonly used for primary and recurrent ICC as well as liver-only and liver-dominant extrahepatic metastatic disease. Currently, the best evidence and most promising results are available for RFA, HAI, TACE, and TARE. In cohort studies, the overall survival rates are similar to those obtained with surgery or systemic therapies. Prospective randomized controlled trials are warranted to compare safety and efficacy between different surgical, interventional, and systemic therapies, as well as their combinations.

(c) 2016 S. Karger GmbH, Freiburg

\section{Introduction}

The aim of this review is to summarize the data on the different locoregional therapies for cholangiocarcinoma (CC), including indications, patient selection, technical effectiveness, complications, and adverse events as well as oncologic efficacy and survival. PubMed was the source for primary selection, whereby publications were extracted by using a search algorithm with the following medical subject heading terms and text words: 'cholangiocarcinoma', 'radiofrequency ablation', 'microwave ablation', 'hepatic artery in-

\section{KARGER}

(c) 2016 S. Karger GmbH, Freiburg

Fax +497614520714 
fusion', 'transarterial chemoembolization', and 'transarterial radioembolization'. Additional publications were identified after crosschecking of the reference lists of the articles extracted by means of primary selection. A description of the different modalities and techniques available for locoregional therapy is not outlined in this overview; however, it can easily be obtained from other publications [1-10].

\section{Locoregional Therapy}

\section{Thermal Ablation}

\section{Radiofrequency Ablation}

A summary of the published data is presented in supplementary table 1 (available at $h t t p: / / w w w . k a r g e r . c o m / P r o d u k t e D B / p r o d u k t e$. asp?doi=453010). In a recent systematic review and meta-analysis, the outcome after radiofrequency ablation (RFA) for unresectable intrahepatic cholangiocarcinoma (ICC) included pooled 1-, 3-, and 5 -year overall survival rates of 82,47 , and $24 \%$, respectively, as well as a pooled local tumor progression rate of $21 \%$ [11]. The therapy of 133 tumors resulted in seven major complications (inclusive of one grade $\mathrm{V}$ complication according to the Clavien-Dindo classification system of surgical complications) or a pooled median major complication rate of $3.8 \%$. The authors concluded that RFA is a therapy that prolongs survival in patients with ICC even in nonsurgical candidates. What is striking about the review is that the results of the analyzed original studies are quite heterogeneous, especially with respect to technical success rates (ranging between 88 and 100\%), technical effectiveness rates (ranging between 66 and 96.2\%), major complication rates (ranging between 0 and $8.3 \%$ ), local tumor progression rates (ranging between 8 and 50\%) as well as median overall survival (ranging between 20 and 60 months) and overall survival rates (e.g. ranging between 21 and $71 \%$ for the 3 -year overall survival). In the following paragraphs, the relevance of patient source (patients with primary ICC vs. those with recurrent ICC) and tumor stage (e.g. tumor number and size and extrahepatic metastatic disease) are outlined in the context of efficacy.

- RFA for primary ICC: There are three articles reporting on RFA for primary ICC. In the largest series with $n=13$ patients and $\mathrm{n}=17$ tumors, technical success and technical effectiveness rates were both $100 \%$ for tumors with a diameter of $0.8-4.5 \mathrm{~cm}$ and for tumor stages between I and IIIb (note: tumors were staged according to Aljiffry et al. [12]) [13]. The corresponding median local recurrence-free and overall survival were 22 and 22 months, respectively. Lack of technical success and technical effectiveness occurred only in 2 patients, both presenting with large tumors ( 7 and $8 \mathrm{~cm}$ ). One of the patients passed away 3.3 months after therapy, and the other patient survived for 13.7 months. In a study from 2010, for RFA of solitary ICC with a diameter of 1-4 cm, the technical success, technical effectiveness, and overall survival rates were $100 \%$ each, and the median overall survival was 20 months [14]. For 2 patients with tumors larger than $5 \mathrm{~cm}$, however, RFA even in combination with bland transarterial embolization was not effective and resulted in incomplete tumor destruction. Notwithstanding, both patients survived for 18 months, with one of them still being alive at the time of publication. In the third study, the primary technical success, technical effectiveness, recurrence-free survival, and overall survival rates were always $100 \%$ for solitary ICC with a diameter of 2.5-3.2 cm [15]. On the contrary, RFA for solitary ICC with a diameter between 4.5 and $7.0 \mathrm{~cm}$ always resulted in technical failure even after two RFA sessions. In all cited studies, the major reasons for surgical unresectability were poor hepatic reserve, comorbidity, patient refusal, and/or central tumor location.

- RFA for recurrent ICC: One original RFA study including patients with exclusively recurrent ICC as well as two original RFA studies providing collectives with a high rate of recurrent CC (85.7 and 58.8\%) were identified [16-18]. In a series of 20 patients and 29 recurrent $\mathrm{CC}$, the median time to recurrence was 7.4 months, and $60 \%$ of the patients showed recurrence within the first year after so-called curative liver resection [18]. The median diameter of the recurrent CC was $1.5 \mathrm{~cm}$. Primary and secondary technical effectiveness rates of percutaneous RFA were 97 and $100 \%$, respectively. The major complication rate was $7 \%$, whereby only grade $\leq$ III complications occurred. The 1 -, 2-, and 4-year local progression-free survival rates were $74 \%$ each, and the mean local progression-free survival was 39.8 months. Again, tumor size turned out as a relevant predictor for survival, with significantly better local progression-free survival for patients with tumors $<1.5 \mathrm{~cm}$ compared with those suffering from tumors $\geq 1.5 \mathrm{~cm}$ in size $(\mathrm{p}=0.041)$. The $1-, 2-$, and 4 -year overall survival rates were 70,60 , and $21 \%$, and the median overall survival was 27.4 months. Butros et al. [16] published results regarding RFA for small ICC. Accordingly, in the 6 patients with eight tumors, the mean time to recurrence after surgical resection was 13 months, and the mean primary and recurrent tumor diameters were 5.5 and $2.3 \mathrm{~cm}$, respectively. The primary and secondary technical effectiveness rates of postoperative RFA were 87.5 and $100 \%$, respectively, and the major complication rate was $0 \%$. The local recurrence-free survival rate and the overall survival rate were $100 \%$, and the median local recurrence-free survival as well as the median overall survival were 49 months. In the study published by Fu et al. [17], recurrent ICC with a diameter ranging between 1.9 and $6.8 \mathrm{~cm}$ were treated with RFA. The negative predictors for a decreased recurrence-free survival and overall survival after RFA were lymph node metastases, poor tumor differentiation, and either multiple tumors or poor tumor differentiation [17].

\section{Microwave Ablation}

Only one specific study on microwave ablation (MWA) as monotherapy for ICC was identified (supplementary table 1) [19]. The series included 15 patients and 24 primary ICC with a diameter of $3.2 \pm 1.9 \mathrm{~cm}$; all patients underwent ultrasound-guided percutaneous MWA [19]. During the follow-up of $12.8 \pm 8.0$ months, the 
technical success, technical effectiveness, and local tumor progression rates were $91.7,87.5$, and $25.0 \%$, respectively. The major complication rate was $20 \%$; only grade $\leq$ III complications occurred. The 1- and 2-year overall survival rates were $60.0 \%$ each. Two further original series report on thermal ablation by means of MWA and RFA $[20,21]$. In the first study, 18 patients with primary ( $\mathrm{n}=$ 8 ) or recurrent $(\mathrm{n}=17)$ ICC were ablated, and followed up for 20.5 \pm 26.3 months [20]. The technical effectiveness and major complication rates were 92.0 and 5.5\%, respectively. The 1-, 3-, and 5-year overall survival rates for the entire collective were $36.3,30.3$, and $30.3 \%$, respectively. For the subgroup of patients suffering from primary ICC, however, the survival was markedly better, with 1-, 3 -, and 5-year overall survival rates of $75.0,62.5$, and $62.5 \%$, respectively. The latter can be explained by the fact that patient source (primary vs. recurrent ICC) - but not gender, number of tumors, therapy modality (MWA vs. RFA), complete ablation, or development of recurrence after ablation - turned out as a predictor for overall survival. The second study including MWA and RFA is a retrospective non-randomized controlled trial [21]. Patients with recurrent ICC were treated with either thermal ablation (77 patients with 133 tumors) or repeated surgical resection (32 patients with 44 tumors). The patient demographics were comparable for both study groups. The median disease-free survival as well as the 1- and 2-year disease-free survival rates were not significantly different between both study groups (thermal ablation: 6.8 months, $33.4 \%$, and $19.7 \%$, respectively, vs. repeated surgical resection: 9.1 months, $37.2 \%$, and $14.9 \%$, respectively). In the subgroup analysis, tumor size ( $\leq 3$ vs. $>3 \mathrm{~cm}$ ) had no impact on the diseasefree survival. Also, the median overall survival as well as the 1-, 2-, and 3-year overall survival rates were not significantly different between both study groups (thermal ablation: 21.3 months, $69.8 \%$, $37.3 \%$, and $20.5 \%$, respectively, vs. repeated surgical resection: 20.3 months, $83.8 \%, 38.0 \%$, and $17.1 \%$, respectively). However, there was a significant survival benefit for the patients with tumors $>3$ $\mathrm{cm}$ when repeated surgical resection instead of thermal ablation was performed. It is also noteworthy that $46.8 \%$ of the included patients received 'preventive' transarterial chemoembolization (TACE).

\section{Transarterial Therapies}

\section{Hepatic Artery Infusion}

A summary of the published data is presented in supplementary table 2 (available at http://www.karger.com/ProdukteDB/produkte. asp?doi=453010). The recently published study by Massani et al. [22] reported single-center results on hepatic artery infusion (HAI) for ICC and compared the outcome with the previously reported literature. After placement of the HAI pump in 11 patients, the mean number of therapy cycles was eight. Each therapy cycle consisted of transarterial infusion of different drugs: $25 \mathrm{mg}$ of folinic acid daily, $8 \mathrm{mg}$ of ondansetron, $4 \mathrm{mg}$ of dexamethasone, and 100 $\mathrm{mg} / \mathrm{m}^{2}$ of each patient's body surface of oxaliplatin (diluted in 100 $\mathrm{ml}$ of $5 \%$ saline solution and infused during $5 \mathrm{~h}$ ) at day 1 as well as $7 \mathrm{mg} / \mathrm{kg}$ of each patient's weight of 5-fluorouracil (5-FU) (diluted in $100 \mathrm{ml}$ of $5 \%$ saline solution and infused with a flow rate of 2 $\mathrm{ml} / \mathrm{h}$ during $24 \mathrm{~h}$ ). Although there were no locoregional complications such as cholecystitis or peptic ulceration, the rates for liver decompensation and hand-foot syndrome were 9.1 and $27.3 \%$, respectively. Tumor control (complete and partial response as well as stable disease according to response evaluation criteria in solid tumors (RECIST)) and overall survival rates were 63.6 and $72.7 \%$, respectively. The median overall survival for the entire collective (11 patients), for the patients with HAI only (8 patients), and for those with HAI in combination with subsequent resection (3 patients) was 17.6, 15.3, and 23.6 months, respectively. For the categorization of these data, the authors performed a literature review with specific inclusion and exclusion criteria. For the seven included studies with a total of 588 patients suffering from different malignant tumors (ICC, extrahepatic cholangiocarcinoma (ECC), gallbladder carcinoma, ampulla carcinoma, and hepatocellular carcinoma), pump-related complication rates ranged between 4.5 and $32.4 \%$ [23-29]. The toxicity rate reached $32.3 \%$ and included also a grade $\mathrm{V}$ adverse event (according to the common terminology criteria for adverse events (CTCAE)) [26, 29]. Partial response, stable disease, and progressive disease rates were 7.7 and $81.4 \%, 41.2$ and $100 \%$ (only hepatocellular carcinoma, $61.1 \%$ for ICC), as well as 0 and $30.8 \%$, respectively $[23-25,28,29]$. It is noteworthy that three original series on HAI for advanced ICC were not mentioned in the above-cited review [30-32]. In two of the studies with a total of 23 patients, repetitive HAI was performed with different regimens including gemcitabine, oxaliplatin, 5-FU, adriamycin, epirubicin, mitomycin C, and/or cisplatin [30, 32]. The tumor control rates were 91.0 and $82.0 \%$, and the overall survival was 9.1 months (median) and 26.0 months (mean). In the third study, Shitara et al. [31] noted the use of HAI with mitomycin $\mathrm{C}$ in combination with degradable starch microspheres. After a total of 204 cycles in 20 patients (median maximum tumor diameter: $7.8 \mathrm{~cm}$, median tumor number: 3, extrahepatic disease rate: $85.0 \%$ ), the tumor response rate was $50.0 \%$ and the median overall survival 14.1 months. Grade III/IV toxicity rates for gastroduodenal ulcer, epigastralgia, anorexia, and nausea/vomiting ranged from 5 to $15 \%$. Only one of the seven studies included HAI exclusively for ICC [23]. In the combined phase I and phase II study, HAI was performed with gemcitabine at doses of $600-1,000 \mathrm{mg} / \mathrm{m}^{2}$ of each patient's weight infused during 30 min at day 1,8 , and 15 every 4 weeks for five cycles. According to the analyses, gemcitabine at a dose of $1,000 \mathrm{mg} / \mathrm{m}^{2}$ of each patient's weight was assumed to be the recommended dose; the corresponding grade IV toxicity (according to CTCAE) and objective tumor response rates were $7.7 \%$ each, and the median overall survival was 389 days. Additionally, Massani et al. [22] performed a review of systemic chemotherapy studies. The seven analyzed studies included a total of 549 patients with different liver malignancies (ICC, ECC, gallbladder carcinoma, and ampulla carcinoma), inhomogeneous pre-treatments (e.g. surgical resection, radiotherapy, chemotherapy, or radiochemotherapy) and tumor stage (e.g. rate and/or type of extrahepatic metastatic disease), as well as a range of different chemotherapy regimens (e.g. folinic acid, 5-FU, and oxaliplatin (FOLFOX) or folinic acid, 5-FU, and 
irinotecan (FOLFIRI)) [33-39]. The listed data include complete response, partial response, stable disease, and progressive disease rates of $0-5.7 \%, 4.2-39.5 \%, 23.3-74.0 \%$, and $17.7-29.4 \%$, respectively $[33,34,36-38]$. The toxicity rates ranged between 0 and $75.0 \%$, and the median overall survival was $7.6-27.7$ months [33, $36,37,39]$. The 1-year overall survival rates were listed in two of the six studies (60.0 and $44.4 \%$ ) and the 2-/3-year overall survival rates only in one other study $(32.0 / 28.0 \%)[38,39]$. The results of a meta-analysis comparing different transarterial therapies including HAI are presented below in the chapter on transarterial radioembolization (TARE) [40].

\section{Transarterial Chemoembolization}

Four review articles analyzed TACE for CC [40-43]. In the first review, Ray et al. [41] included 16 studies with a total of 542 patients undergoing chemotherapy-based transarterial therapy, whereas in all studies - except in the study by Andrasina et al. [44] - repetitive TACE was performed in a typical fashion with transarterial injection of one or more chemotherapeutic agents and one or more embolic agents [41]. After pooling, the tumor control, severe toxicity, 30-day mortality, and 1-year overall survival rates were $76.8,18.9,0.7$, and $58.0 \%$, respectively. In the systematic review by Yang et al. [43], 13 studies with a total of 504 patients undergoing TACE for unresectable CC were analyzed regarding definition of response (RECIST), overall survival, and toxicity. Under consideration of the listed data, the progressive disease rate was $0-60.0 \%$ and the progression-free survival ranged from 1.8 to 10.0 months [45-48]. The 6-month, 1-year, 2-year, 3-year, and 5-year overall survival rates were $64.0-100 \%, 38.0-78.0 \%, 12.0-38.0 \%$, $4.0-30.0 \%$, and $0-8.0 \%$, respectively $[45,46,49-53]$. The acuity of toxicity was $<30$ days in six studies, 10 days in one study, $<3$ days in two studies, and not indicated in four studies. The overall toxicity rates ranged from 17.0 to $65.0 \%$, whereas grade I/II and grade III/ IV toxicity rates (according to the World Health Organization (WHO) toxicity grades) were $38.0-65.0 \%$ and $3.0-37.0 \%$, respectively [49-51, 54]. Seidensticker et al. [42] summarized patient and tumor characteristics and the oncologic outcome for different TACE studies on CC. For nine original series with 391 patients, the extrahepatic disease, prior systemic chemotherapy, and prior liverdirected therapy rates were $29.4-54.0 \%, 19.0-83.3 \%$, and $8.0-$ $41.7 \%$, respectively $[47,48,51,55]$. The median overall survival for therapy and diagnosis were 12.0-23.0 and 10.0-16.3 months, respectively, and the objective response (complete and partial response) rate ranged from $4 \%$ (RECIST) to $80 \%$ (mRECIST) $[46,47$, $49,51,55,56]$. The results of a meta-analysis comparing different transarterial therapies for unresectable ICC including different TACE techniques are presented below [40]. The listed data demonstrate that repetitive TACE is safe and effective for the treatment of liver-only and liver-dominant CC whenever the adequate embolization technique and different embolic and chemotherapeutic agents are used. No more retrospective single-center studies are needed in this context; it is rather time for standardization and randomized trials under consideration of the published promising TACE data.
- Different TACE techniques: There are three different TACE techniques: conventional TACE (cTACE), degradable starch microspheres TACE (DSM-TACE), and drug-eluting bead TACE (DEB-TACE). A detailed summary of the published data is presented in supplementary table 3 (available at $h t t p: / / w w w$. karger.com/ProdukteDB/produkte.asp?doi=453010), and the results of meta-analyses are presented in the chapter on TARE.

- TACE in comparison or combined with other therapies: In different studies, TACE was compared or combined with other therapies/controls: TACE versus surgical resection, TACE in combination with surgical resection (adjuvant TACE), TACE versus systemic chemotherapy, TACE in combination with systemic chemotherapy, TACE versus other transarterial therapies as well as TACE versus best supportive care (BSC) or no therapy. A detailed summary of the published data is presented in supplementary table 3 , and the results of meta-analyses are presented in the following chapter on TARE.

\section{Transarterial Radioembolization}

A summary of the published data is presented in supplementary

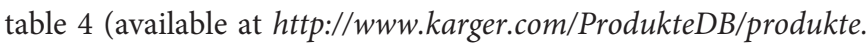
asp?doi=453010). Recently, at least two systemic meta-analyses were published on TARE for ICC [40, 43]. In the first article, clinical outcomes and complications were assessed for different transarterial therapies including TACE, transarterial chemoperfusion (TACP), and TARE [43]. After analysis of 22 original studies (929 patients) including TARE, cTACE, DSM-TACE, and TACP, Yang et al. [43] reported pooled data for all therapies, i.e. overall and mild-to-moderate 30 -day toxicity rates of 34.9 and $22.4 \%$, a 30 -day mortality rate of $0.6 \%$, complete and partial response rates of 10 and $22.2 \%$, a median overall survival of 12.4 months, and a 1-year overall survival rate of $53.0 \%$. Multiple and/or infiltrating tumors as well as worse Eastern Cooperative Oncology Group (ECOG) performance status was a negative predictor for increased overall survival in some original TARE studies [57-59]. In comparison, tumor hypovascularity was a negative predictor only for DSMTACE and TACP $[46,60]$. In the second article, different transarterial therapies were compared systematically [40]. For a total of 657 patients (20 original studies), the grade III/IV toxicity (events per patient) was highest for HAI (0.35) versus cTACE (0.26) versus DEB-TACE (0.32), the response rate (complete and partial) was highest for HAI (56.9\%) versus TARE (27.9\%) versus cTACE (17.3\%), and the overall survival (median) was highest for HAI (22.8 months) versus TARE (13.9 months) versus cTACE (12.4 months) versus DEB-TACE (12.3 months). Although the patient and tumor characteristics were markedly different in the four therapy groups - e.g. higher rate of extrahepatic disease for cTACE (48.0\%) versus HAI (36.1\%) and ECOG performance status 1, 2, and 3 for TARE (57.4\%) and CTACE (42.0\%) versus HAI (24\%) -, the authors concluded that HAI results in the best tumor response, except that the survival after HAI may be limited by toxicity.

- Prospective series: A total of six prospective original series with TARE for CC were identified [59, 61-65]. All the studies included patients with advanced tumor stages and/or after failure 
of first-, second-, and/or third-line therapies as suggested by the extrahepatic disease rate $(31.0-76.5 \%)$, prior chemotherapy rate (29.0-100\%), and prior liver-directed therapy rate (21.0$56.0 \%)$. The objective response rates after TARE range markedly between the different studies but also in one and the same study since different classification systems (RECIST, PET Response Criteria In Solid Tumors (PERCIST), and/or European Association for the Study of the Liver (EASL) criteria) were used and compared. Accordingly, Ibrahim et al. [64] reported objective response rates of $27.0 \%$ for RECIST but $77.0 \%$ for EASL. Similarily, Camacho et al. [61] published response rates of $0 \%$ for RECIST and $77.7 \%$ for PRECIST. For the cited original TARE studies, the overall survival from diagnosis and from TARE was 20.4-25.1 and 9.3-16.3 months, respectively [59, 61, 65]. Four of the six cited studies - all of them with grade II level of evidence (according to the National Health and Medical Research evidence hierarchy) - were included in a review article with a specific analysis of toxicity $[43,59,63-65]$. The acuity of toxicity was published in two studies, with $<30$ days and 2 days being listed $[59,63]$. Only one original study reported on the overall toxicity rate (89.0\%) [65]. Data on the severity of toxicity were indicated in all four studies, with a grade III/IV toxicity rate (according to WHO toxicity grades) ranging from 0 to $11 \%[63,65]$. The grade I/II toxicity rate, however, was published in only one of the four studies and amounted to 79\% [59].

\section{Discussion}

Regarding the multiple available locoregional therapies for ICC, there is a lack of prospective randomized controlled trials. Controlled case series (unfiltered data) were identified for RFA and MWA (vs. surgical resection) as well as for TACE (vs. surgical resection, systemic chemotherapy, BSC, and/or no therapy). Additionally, overview and review articles including systematic metaanalyses (filtered information) were identified for RFA (including patients with primary and/or recurrent ICC) and different transarterial therapies such as HAI, TACE, and TARE (including patients with liver-only and liver-dominant extrahepatic metastatic disease). Critical analysis of those articles, however, resulted in the detection of at least in parts striking discrepancies between the data presented in the overview and review articles and in the original publication. On the basis of the very promising original data published for liver-targeted therapies, prospective randomized controlled trials can overcome study bias such as heterogeneous patient and tumor characteristics and inconsistent therapeutic regimens. After a review of the literature, four aspects are worthy of discussion in the context of locoregional therapy and CC: (i) Is the oncologic outcome after RFA and TACE comparable with surgical resection in selected patients?; (ii) adjuvant TACE might offer an advantage in the adjuvant setting in patients with high risk for early intrahepatic recurrence and should be evaluated in trials; (iii) RFA, MWA, and different transarterial therapies are safe and highly effective for both recurrent ICC after potentially curative surgical resection or thermal ablation and for conversion to resectability (neoadjuvant locoregional therapy); and (iv) chemotherapybased transarterial therapies show a survival benefit and improve the quality of life in patients with liver-only and liver-dominant extrahepatic metastatic disease when compared with systemic chemotherapy, BSC, and/or no therapy; however, data from prospective trials is lacking. With a focus on technical issues, for thermal ablation, homogeneous ablation zones (considering the desmoplastic growth pattern of ICC) and homogeneous safety margins of at least $1 \mathrm{~cm}$ (due to the ill-defined margins of ICC on computed tomography/magnetic resonance imaging/ultrasound) and for different transarterial therapies, optimization of the protocols (e.g. doses and types of chemotherapeutic agents, types and sizes of embolic agents, internal radiation dose, treatment intervals, and response evaluation) are of particular relevance $[3,4,6,18]$. For the future, complex multimodal concepts are the key to further improve progression-free and overall survival as well as the quality of life in patients with CC in different stages. For example, Andrasina et al. [44] presented an interdisciplinary approach for symptomatic irresectable ICC and ECC by means of biliary stent implantation, brachytherapy, and chemotherapy. After successful biliary drainage (metallic stent placement and intraluminal brachytherapy), patients were assigned either to an arm with transarterial chemotherapy (for patients with hypervascular tumors) or to an arm with intravenous chemotherapy (for patients with hypovascular tumors). A total of 17 patients received transarterial chemotherapy, either as HAI or TACE. Intravenous chemotherapy was performed in 23 patients. For transarterial chemotherapy and intravenous chemotherapy, the median overall survival was 25.2 and 11.5 months, respectively, and the 1-, 2-, and 3-year overall survival rates were 88.2 and $43.5 \%, 52.9$ and $25.4 \%$, and 10.1 and $0 \%$, respectively ( $\mathrm{p}<0.05$ for the overall survival). Multiple other publications present concepts combining established and advanced interdisciplinary therapies such as MWA in combination with TACE or RFA in combination with systemic molecular therapies [66-70]. Such innovative concepts should be furthered continuously.

\section{Disclosure Statement}

All authors declare that there is nothing to disclose regarding this article. 


\section{References}

1 Mahnken AH: Current status of transarterial radioembolization. World J Radiol 2016;8:449-459.

2 Mahnken AH, Pereira PL, de Baere T: Interventional oncologic approaches to liver metastases. Radiology 2013;266:407-430.

3 Massmann A, Rodt T, Marquardt S, Seidel R, Thomas K, Wacker F, Richter GM, Kauczor HU, Bucker A, Pereira PL, Sommer CM: Transarterial chemoembolization (TACE) for colorectal liver metastases - current status and critical review. Langenbecks Arch Surg 2015;400:641-659.

4 Padia SA: Intrahepatic cholangiocarcinoma. Tech Vasc Interv Radiol 2015;18:227-235.

5 Singla N, Gahan J: New technologies in tumor ablation. Curr Opin Urol 2016;26:248-253.

6 Pereira PL, Sommer CM: Modern Practice of Transarterial Tumour Therapy: of the Liver. Bremen, UNIMED Science, 2015.

7 Vogl TJ, Zangos S, Eichler K, Gruber-Rouh T, Hammerstingl RM, Trojan J, Weisser P: Radiological diagnosis and intervention of cholangiocarcinomas (CC) (Article in German). Rofo 2012;184:883-892.

8 Wells SA, Hinshaw JL, Lubner MG, Ziemlewicz TJ, Brace CL, Lee FT Jr: Liver ablation: best practice. Radiol Clin North Am 2015;53:933-971.

9 Yao D, Kunam VK, Li X: A review of the clinical diagnosis and therapy of cholangiocarcinoma. J Int Med Res 2014;42:3-16.

10 Ziemlewicz TJ, Wells SA, Lubner MG, Brace CL, Lee FT Jr, Hinshaw JL: Hepatic tumor ablation. Surg Clin North Am 2016;96:315-339.

11 Han K, Ko HK, Kim KW, Won HJ, Shin YM, Kim PN: Radiofrequency ablation in the treatment of unresectable intrahepatic cholangiocarcinoma: systematic review and meta-analysis. J Vasc Interv Radiol 2015;26: 943-948.

12 Aljiffry M, Walsh MJ, Molinari M: Advances in diagnosis, treatment and palliation of cholangiocarcinoma: 1990-2009. World J Gastroenterol 2009;15:4240-4262.

13 Kim JH, Won HJ, Shin YM, Kim KA, Kim PN: Radiofrequency ablation for the treatment of primary intrahepatic cholangiocarcinoma. AJR Am J Roentgenol 2011;196:W205-209.

14 Carrafiello G, Lagana D, Cotta E, Mangini M, Fontana F, Bandiera F, Fugazzola C: Radiofrequency ablation of intrahepatic cholangiocarcinoma: preliminary experience. Cardiovasc Intervent Radiol 2010;33:835-839.

15 Giorgio A, Calisti G, DE Stefano G, Farella N, DI Sarno A, Amendola F, Scognamiglio U, Giorgio V: Radiofrequency ablation for intrahepatic cholangiocarcinoma: retrospective analysis of a single centre experience. Anticancer Res 2011;31:4575-4580.

16 Butros SR, Shenoy-Bhangle A, Mueller PR, Arellano RS: Radiofrequency ablation of intrahepatic cholangiocarcinoma: feasability, local tumor control, and long term outcome. Clin Imaging 2014;38:490-494.

17 Fu Y, Yang W, Wu W, Yan K, Xing BC, Chen MH: Radiofrequency ablation for postoperative recurrences of intrahepatic cholangiocarcinoma. Chin J Cancer Res 2011;23:295-300.

18 Kim JH, Won HJ, Shin YM, Kim PN, Lee SG, Hwang $S$ : Radiofrequency ablation for recurrent intrahepatic cholangiocarcinoma after curative resection. Eur J Radiol 2011;80:e221-225.

19 Yu MA, Liang P, Yu XL, Cheng ZG, Han ZY, Liu FY, Yu J: Sonography-guided percutaneous microwave ablation of intrahepatic primary cholangiocarcinoma. Eur J Radiol 2011;80:548-552.

20 Xu HX, Wang Y, Lu MD, Liu LN: Percutaneous ultrasound-guided thermal ablation for intrahepatic cholangiocarcinoma. Br J Radiol 2012;85:1078-1084.
Zhang SJ, Hu P, Wang N, Shen Q, Sun AX, Kuang M, Qian GJ: Thermal ablation versus repeated hepatic resection for recurrent intrahepatic cholangiocarcinoma. Ann Surg Oncol 2013;20:3596-3602.

22 Massani M, Nistri C, Ruffolo C, Bonariol R, Pauletti B, Bonariol L, Caratozzolo E, Morana G, Bassi N: Intrahepatic chemotherapy for unresectable cholangiocarcinoma: review of literature and personal experience. Updates Surg 2015;67:389-400

23 Inaba Y, Arai Y, Yamaura H, Sato Y, Najima M, Aramaki T, Sone M, Kumada T, Tanigawa N, Anai H, Yoshioka T, Ikeda M; Japan Interventional Radiology in Oncology Study Group (JIVROSG): Phase I/II study of hepatic arterial infusion chemotherapy with gemcitabine in patients with unresectable intrahepatic cholangiocarcinoma (JIVROSG-0301). Am J Clin Oncol 2011;34:58-62.

24 Jarnagin WR, Schwartz LH, Gultekin DH, Gonen M, Haviland D, Shia J, D'Angelica M, Fong Y, Dematteo R, Tse A, Blumgart LH, Kemeny N: Regional chemotherapy for unresectable primary liver cancer: results of a phase II clinical trial and assessment of DCE-MRI as a biomarker of survival. Ann Oncol 2009;20;1589-1595.

25 Kemeny NE, Schwartz L, Gonen M, Yopp A, Gultekin D, D’Angelica MI, Fong Y, Haviland D, Gewirtz AN, Allen P, Jarnagin WR: Treating primary liver cancer with hepatic arterial infusion of floxuridine and dexamethasone: does the addition of systemic bevacizumab improve results? Oncology 2011;80:153-159.

26 Mambrini A, Guglielmi A, Pacetti P, Iacono C, Torri T, Auci A, Nicoli N, Orlandi M, Guadagni S, Fiorentini $\mathrm{G}$, Cantore M: Capecitabine plus hepatic intra-arterial epirubicin and cisplatin in unresectable biliary cancer: a phase II study. Anticancer Res 2007;27:3009-3013.

27 Sinn M, Nicolaou A, Gebauer B, Podrabsky P, Seehofer D, Ricke J, Dorken B, Riess H, Hildebrandt B: Hepatic arterial infusion with oxaliplatin and 5-FU/folinic acid for advanced biliary tract cancer: a phase II study. Dig Dis Sci 2013;58:2399-2405.

28 Subbiah IM, Subbiah V, Tsimberidou AM, Naing A, Kaseb AO, Javle M, Fu S, Hong DS, Piha-Paul S, Wheler JJ, Hess KR, Janku F, Falchook GS, Wolff RA, Kurzrock R: Targeted therapy of advanced gallbladder cancer and cholangiocarcinoma with aggressive biology: eliciting early response signals from phase 1 trials. Oncotarget 2013;4:153-162.

29 Valle J, Wasan H, Palmer DH, Cunningham D, Anthoney A, Maraveyas A, Madhusudan S, Iveson T, Hughes S, Pereira SP, Roughton M, Bridgewater J; ABC-02 Trial Investigators: Cisplatin plus gemcitabine versus gemcitabine for biliary tract cancer. New Engl J Med 2010;362:1273-1281.

30 Ghiringhelli F, Lorgis V, Vincent J, Ladoire S, Guiu B: Hepatic arterial infusion of gemcitabine plus oxaliplatin as second-line treatment for locally advanced intrahepatic cholangiocarcinoma: preliminary experience. Chemotherapy 2013;59:354-360.

31 Shitara K, Ikami I, Munakata M, Muto O, Sakata Y: Hepatic arterial infusion of mitomycin $\mathrm{C}$ with degradable starch microspheres for unresectable intrahepatic cholangiocarcinoma. Clin Oncol 2008;20:241-246.

32 Tanaka N, Yamakado K, Nakatsuka A, Fujii A, Matsumura K, Takeda K: Arterial chemoinfusion therapy through an implanted port system for patients with unresectable intrahepatic cholangiocarcinoma - initial experience. Eur J Radiol 2002;41:42-48.

33 Croitoru A, Gramaticu I, Dinu I, Gheorghe L, Alexandrescu S, Buica F, Luca I, Becheanu G, Herlea V, Simionov I, Hrehoret D, Lupescu I, Popescu I, Diculescu M: Fluoropyrimidines plus cisplatin versus gemcitabine/gemcitabine plus cisplatin in locally advanced and metastatic biliary tract carcinoma - a retrospective study. J Gastrointestin Liver Dis 2012;21:277-284.
Eckmann KR, Patel DK, Landgraf A, Slade JH, Lin E, Kaur H, Loyer E, Weatherly JM, Javle M: Chemotherapy outcomes for the treatment of unresectable intrahepatic and hilar cholangiocarcinoma: a retrospective analysis. Gastrointest Cancer Res 2011;4:155-160.

35 Kim MJ, Oh DY, Lee SH, Kim DW, Im SA, Kim TY, Heo DS, Bang YJ: Gemcitabine-based versus fluoropyrimidine-based chemotherapy with or without platinum in unresectable biliary tract cancer: a retrospective study. BMC Cancer 2008;8:374.

36 Lee GW, Kang JH, Kim HG, Lee JS, Lee JS, Jang JS: Combination chemotherapy with gemcitabine and cisplatin as first-line treatment for immunohistochemically proven cholangiocarcinoma. Am J Clin Oncol 2006;29:127-131.

37 Park SH, Park YH, Lee JN, Bang SM, Cho EK, Shin $\mathrm{DB}$, Lee JH: Phase II study of epirubicin, cisplatin, and capecitabine for advanced biliary tract adenocarcinoma. Cancer 2006; 106:361-365.

38 Sasaki T, Isayama H, Nakai Y, Mizuno S, Yamamoto K, Yagioka H, Yashima Y, Kawakubo K, Kogure H, Togawa O, Matsubara S, Ito Y, Sasahira N, Hirano K, Tsujino T, Toda N, Tada M, Omata M, Koike K: Multicenter phase II study of S-1 monotherapy as secondline chemotherapy for advanced biliary tract cancer refractory to gemcitabine. Invest New Drugs 2012;30: 708-713.

39 Wiazzane N, Chauffert B, Ghiringhelli F: Retrospective analysis of survival benefits of chemotherapy for metastatic or non-resectable intrahepatic cholangiocarcinoma. Clin Res Hepatol Gastroenterol 2013;37:614-618.

40 Boehm LM, Jayakrishnan TT, Miura JT, Zacharias AJ, Johnston FM, Turaga KK, Gamblin TC: Comparative effectiveness of hepatic artery based therapies for unresectable intrahepatic cholangiocarcinoma. J Surg Oncol 2015;111:213-220.

41 Ray CE Jr, Edwards A, Smith MT, Leong S, Kondo K, Gipson M, Rochon PJ, Gupta R, Messersmith W, Purcell T, Durham J: Metaanalysis of survival, complications, and imaging response following chemotherapybased transarterial therapy in patients with unresectable intrahepatic cholangiocarcinoma. J Vasc Interv Radiol 2013;24:1218-1226.

42 Seidensticker R, Ricke J, Seidensticker M: Integration of chemoembolization and radioembolization into multimodal treatment of cholangiocarcinoma. Best Pract Research Clin Gastroenterol 2015;29:319-332.

43 Yang L, Shan J, Shan L, Saxena A, Bester L, Morris DL: Trans-arterial embolisation therapies for unresectable intrahepatic cholangiocarcinoma: a systematic review. J Gastrointest Oncol 2015;6:570-588.

44 Andrasina T, Valek V, Panek J, Kala Z, Kiss I, Tucek S, Slampa P: Multimodal oncological therapy comprising stents, brachytherapy, and regional chemotherapy for cholangiocarcinoma. Gut Liver 2010;4(suppl 1):S82-88.

45 Aliberti C, Benea G, Tilli M, Fiorentini G: Chemoembolization (TACE) of unresectable intrahepatic cholangiocarcinoma with slow-release doxorubicin-eluting beads: preliminary results. Cardiovasc Intervent Radiol 2008;31:883-888.

46 Kim JH, Yoon HK, Sung KB, Ko GY, Gwon DI, Shin JH, Song HY: Transcatheter arterial chemoembolization or chemoinfusion for unresectable intrahepatic cholangiocarcinoma: clinical efficacy and factors influencing outcomes. Cancer 2008;113:1614-1622.

47 Kuhlmann JB, Euringer W, Spangenberg HC, Breidert M, Blum HE, Harder J, Fischer R: Treatment of unresectable cholangiocarcinoma: conventional transarterial chemoembolization compared with drug eluting bead-transarterial chemoembolization and systemic chemotherapy. Eur J Gastroenterol Hepatol 2012;24: 437-443. 
48 Poggi G, Amatu A, Montagna B, Quaretti P, Minoia C, Sottani C, Villani L, Tagliaferri B, Sottotetti F, Rossi O, Pozzi E, Zappoli F, Riccardi A, Bernardo G: OEMTACE: a new therapeutic approach in unresectable intrahepatic cholangiocarcinoma. Cardiovasc Intervent Radiol 2009;32:1187-1192.

49 Burger I, Hong K, Schulick R, Georgiades C, Thuluvath P, Choti M, Kamel I, Geschwind JF: Transcatheter arterial chemoembolization in unresectable cholangiocarcinoma: initial experience in a single institution. J Vasc Intervent Radiol 2005; 16:353-361.

50 Gusani NJ, Balaa FK, Steel JL, Geller DA, Marsh JW, Zajko AB, Carr BI, Gamblin TC: Treatment of unresectable cholangiocarcinoma with gemcitabine-based transcatheter arterial chemoembolization (TACE): a single-institution experience. J Gastrointest Surg 2008; 12:129-137.

51 Park SY, Kim JH, Yoon HJ, Lee IS, Yoon HK, Kim KP: Transarterial chemoembolization versus supportive therapy in the palliative treatment of unresectable intrahepatic cholangiocarcinoma. Clin Radiol 2011;66: 322-328.

52 Scheuermann U, Kaths JM, Heise M, Pitton MB Weinmann A, Hoppe-Lotichius M, Otto G: Comparison of resection and transarterial chemoembolisation in the treatment of advanced intrahepatic cholangiocarcinoma - a single-center experience. Eur J Surg Oncol 2013;39:593-600

53 Vogl TJ, Naguib NN, Nour-Eldin NE, Bechstein WO, Zeuzem S, Trojan J, Gruber-Rouh T: Transarterial chemoembolization in the treatment of patients with unresectable cholangiocarcinoma: results and prognostic factors governing treatment success. Int J Cancer 2012;131:733-740.

54 Kiefer MV, Albert M, McNally M, Robertson M, Sun W, Fraker D, Olthoff K, Christians K, Pappas S, Rilling W, Soulen MC: Chemoembolization of intrahepatic cholangiocarcinoma with cisplatinum, doxorubicin, mitomycin C, ethiodol, and polyvinyl alcohol: a 2-center study. Cancer 2011;117:1498-1505.

55 Schiffman SC, Reuter NP, McMasters KM, Scoggins CR, Martin RC: Overall survival peri-hilar cholangiocarcinoma: R1 resection with curative intent compared to primary endoscopic therapy. J Surg Oncol 2012;105: 91-96.
56 Herber S, Otto G, Schneider J, Manzl N, Kummer I, Kanzler S, Schuchmann A, Thies J, Duber C, Pitton M: Transarterial chemoembolization (TACE) for inoperable intrahepatic cholangiocarcinoma. Cardiovasc Intervent Radiol 2007;30:1156-1165.

57 Hoffmann RT, Paprottka PM, Schon A, Bamberg F, Haug A, Durr EM, Rauch B, Trumm CT, Jakobs TF, Helmberger TK, Reiser MF, Kolligs FT: Transarterial hepatic yttrium-90 radioembolization in patients with unresectable intrahepatic cholangiocarcinoma: factors associated with prolonged survival. Cardiovasc Intervent Radiol 2012;35:105-116.

58 Mouli S, Memon K, Baker T, Benson AB 3rd, Mulcahy MF, Gupta R, Ryu RK, Salem R, Lewandowski RJ: Yttrium-90 radioembolization for intrahepatic cholangiocarcinoma: safety, response, and survival analysis. J Vasc Intervent Radiol 2013;24:1227-1234.

59 Saxena A, Chua TC, Bester L, Kokandi A, Morris DL: Factors predicting response and survival after yttrium90 radioembolization of unresectable neuroendocrine tumor liver metastases: a critical appraisal of 48 cases. Ann Surg 2010;251:910-916.

60 Vogl TJ, Dommermuth A, Heinle B, Nour-Eldin NE, Lehnert T, Eichler K, Zangos S, Bechstein WO, Naguib $\mathrm{NN}$ : Colorectal cancer liver metastases: long-term survival and progression-free survival after thermal ablation using magnetic resonance-guided laser-induced interstitial thermotherapy in 594 patients: analysis of prognostic factors. Invest Radiol 2014;49:48-56.

61 Camacho JC, Kokabi N, Xing M, Prajapati HJ, ElRayes B, Kim HS: Modified response evaluation criteria in solid tumors and European Association for the Study of the Liver criteria using delayed-phase imaging at an early time point predict survival in patients with unresectable intrahepatic cholangiocarcinoma following yttrium-90 radioembolization. J Vasc Interv Radiol 2014;25:256-265.

62 Filippi L, Pelle G, Cianni R, Scopinaro F, Bagni O: Change in total lesion glycolysis and clinical outcome after ${ }^{90} \mathrm{Y}$ radioembolization in intrahepatic cholangiocarcinoma. Nucl Med Biol 2015;42:59-64.
63 Haug AR, Heinemann V, Bruns CJ, Hoffmann R, Jakobs T, Bartenstein P, Hacker M: ${ }^{18}$ F-FDG PET independently predicts survival in patients with cholangiocellular carcinoma treated with ${ }^{90} \mathrm{Y}$ microspheres. Eur J Nucl Med Mol Imaging 2011;38:1037-1045.

64 Ibrahim SM, Mulcahy MF, Lewandowski RJ, Sato KT, Ryu RK, Masterson EJ, Newman SB, Benson A 3rd, Omary RA, Salem R: Treatment of unresectable cholangiocarcinoma using yttrium-90 microspheres: results from a pilot study. Cancer 2008;113:2119-2128.

65 Rafi S, Piduru SM, El-Rayes B, Kauh JS, Kooby DA, Sarmiento JM, Kim HS: Yttrium-90 radioembolization for unresectable standard-chemorefractory intrahepatic cholangiocarcinoma: survival, efficacy, and safety study. Cardiovasc Intervent Radiol 2013;36:440-448.

66 Gadaleta CD, Ranieri G: Trans-arterial chemoembolization as a therapy for liver tumours: new clinical developments and suggestions for combination with angiogenesis inhibitors. Crit Rev Oncol Hematol 2011; 80:40-53.

67 Qiu J, Chen S, Wu H: Long-term outcomes after hepatic resection combined with radiofrequency ablation for initially unresectable multiple and bilobar liver malignancies. J Surg Res 2014;188:14-20.

68 Seidensticker R, Seidensticker M, Doegen K, Mohnike K, Schutte K, Stubs P, Kettner E, Pech M, Amthauer H, Ricke J: Extensive use of interventional therapies improves survival in unresectable or recurrent intrahepatic cholangiocarcinoma. Gastroenterol Res Pract 2016;2016:8732521.

69 Shah KN, Clary BM: Endoscopic and percutaneous approaches to the treatment of biliary tract and primary liver tumors: controversies and advances. Surg Oncol Clin North Am 2014;23:207-230.

70 Yang GW, Zhao Q, Qian S, Zhu L, Qu XD, Zhang W, Yan ZP, Cheng JM, Liu QX, Liu R, Wang JH: Percutaneous microwave ablation combined with simultaneous transarterial chemoembolization for the treatment of advanced intrahepatic cholangiocarcinoma. Onco Targets Ther 2015;8:1245-1250. 